\title{
COMFORT BASED SEAT SELECTION TO MINIMIZE 6 DOF WHOLE- BODY VIBRATION IN INTEGRATED STEEL MANUFACTURING MOBILE MACHINERY
}

\author{
*Michele Oliver ${ }^{1}$, Leanne Conrad ${ }^{1}$, Robert J. Jack ${ }^{1,3}$, James P. Dickey ${ }^{2}$, \\ Tammy Eger ${ }^{3}$
}

\author{
1. University of Guelph, Guelph, Ontario, Canada \\ 2. University of Western Ontario, London Ontario, Canada \\ 3. Laurentian University, Sudbury, Ontario, Canada
}

\begin{abstract}
Introduction
Operators of heavy machinery are often exposed to complex whole-body vibration (WBV) involving simultaneous motion along three translational and three rotational axes (6-DOF). When companies retrofit machines, seats are usually selected and implemented without testing using machine and/or terrain specific vibration inputs to assess seat efficacy. The purpose of this project was to provide the steel industry and others with information which would allow them to more efficiently retrofit existing machines.
\end{abstract}

\section{Methods}

Six-DOF chassis acceleration data were recorded for various mobile machines from the steel making industry. ${ }^{1}$ Six, 20 second representative profiles (Table 1) were assembled from the 'worst' WBV machine for use in this seat selection study. Profiles were implemented while subjects sat on one of three heavy equipment seats (BeGe7150, Grammar MSG 95G1721, and a 6801 Isringhausen in which the seat pan cushion was retrofitted with Skydex ${ }^{\mathrm{TM}}$ seating material) mounted on a 6 DOF Parallel Robotics System Corporation (PRSCO) robot. Three randomized trials of each combination of seat and profile were conducted using 8 male $(22.3 \pm 2.0$ yrs $)$ and 8 female $(23.5 \pm 1.8 \mathrm{yrs})$ inexperienced operators as well as 4 male $(47.3 \pm 12.3 \mathrm{yrs})$ experienced operators from a participating steel making company. All subjects provided informed consent and all laboratory procedures were approved by the Research Ethics Board at the University of Guelph. Assessment variables included operator reported normalized (to the operator's mean response) comfort (ORC) which was verbally reported by subjects following each vibration exposure according to methods reported in Dickey et al. ${ }^{2}$ The other assessment variable was 6 DOF VTV Weighted Comfort (VTVC) which was assessed using a 6-DOF seat pad transducer according to ISO 2631-1 standards. ${ }^{3}$

\section{Results}

For inexperienced operators, factorial ANOVA procedures revealed no significant $(\mathrm{p} \leq 0.01)$ differences between seats, sex or trials for ORC; however, Bonferroni posthoc procedures showed that all of the profiles were different from one another $(\mathrm{p} \leq 0.01)$. For the VTVC, a significant difference was observed between seats with the 
BeGe7150 resulting in the lowest VTVC value followed by the Grammar MSG 95G1721 and finally the 6801 Isringhausen. Unlike results for ORC, the VTVC for profile 1 was not significantly different than profile 3 . A significant interaction between profile and seat was obtained, indicating that VTVC values were different for various combinations of profile and seat.

For experienced subjects, results were the same as inexperienced subjects for ORC with the exception that profiles 5 and 6 were not different from one another. Unlike the inexperienced subjects, for VTVC, there were no significant differences between seats, but all profiles were found to be different from one another with the exception of profiles 4 and 6 .

\begin{tabular}{|c|c|c|}
\hline Profile & ProfileTask/Condition & 6-DOF Unweighted Chassis Vibration Total Value $\left(\mathrm{m} / \mathrm{s}^{2}\right)$ \\
\hline 1 & Driving Loaded & 2.122 \\
\hline 2 & Driving Loaded & 1.247 \\
\hline 3 & Driving Unloaded & 2.168 \\
\hline 4 & Driving Unloaded & 1.442 \\
\hline 5 & Slag Pot Pickup & 1.028 \\
\hline 6 & Pot Banging & 1.816 \\
\hline
\end{tabular}

Table 1. 6-DOF Vibration total value (VTV) and corresponding field tasks for each of the six vibration profiles. Profiles were developed from a Pot Hauler ${ }^{1}$.

\section{Discussion}

In the inexperienced operators, the best seat was found to be the BeGe7150 (from VTVC); however, in the small number of experienced subjects, neither ORC nor VTVC resulted in a 'clear cut' seat selection. One of the potential reasons for this is that all three tested seats were considered to be higher end seats and were much better than the seats currently used by the operators in their jobs. The significant interaction effect found between profile and seat in both the inexperienced and experienced operators shows clearly that from a comfort perspective, there may not be one best seat for all of the different vibration profiles encountered in an operator's daily routine.

\section{References}

1. Oliver, M, Jack, J., Eger, T., Dickey, J., Conrad, L., and Harnish, C. 2009 Quantification and characterization of 6-degree-of-freedom whole-body vibration exposure spectra from the chassis of selected mobile machines used in the steel making industry. Proceedings of the 4th International Conference on Whole-body Vibration Injuries, Montreal, Quebec.

2. Dickey, J.P., Eger, T.R., Oliver, M.L., Boileau, P.E., Trick, L.M., \& Edwards, A.M. 2007. Multi-axis sinusoidal whole-body vibrations: Part II - Relationship between Vibration Total Value and discomfort varies between vibration axes. Journal of Low Frequency Noise Vibration and Active Control, 26, (3) 195-204.

3. ISO 2631/1 1997, Mechanical vibration and shock - Evaluation of human exposure to whole-body vibration - Part 1: General requirements, International Standards Organization, Geneva, Switzerland. 